\title{
KRONIK
}

\section{Bir Finans Gurusu ile Kriz Üzerine}

Yrd. Doç. Dr. Serdal Bahçe, A.Ü. Siyasal Bilgiler Fakültesi, Maliye Bölümü

New Left Review'in son sayısında (Eylül-Ekim 2012, Say1 77), eski finansçı ve yazar Richard Duncan ile yapılmış bir söyleşi yer almakta. Dergi söyleşiyi "Yeni Bir Küresel Depresyon mu?" başlığıyla yayınladı. Richard Duncan uzun yıllar boyunca pek çok ülkede finansal yatırım şirketlerinde ve Bretton Woods kurumlarında çalışmış bir araştırmacıdır. 2003 yılında yazdığı The Dollar Crisis kitabında, uyarıları dikkate alınmayan pek çok diğer münafık yazar gibi, krizin gelmekte olduğunu haber vermiştir. Bu yıl basılan The New Depression adlı kitabı ise söyleşinin esin kaynağı olmuş. Söyleşi ampirik verilerle desteklenmiş, oldukça kapsamlı ve aydınlatıcı bir söyleşidir. Söyleşide krizin yapısal, ekonomik ve siyasal kökenleri ve krizden çıkışın muhtemel yolları üzerine önemli belirlemeler mevcut.

Söyleşinin başında Duncan kendi hayat hikayesi üzerinden kriz ile ilgili bilgi donanımının nasıl oluştuğunu açıklamakta. Pek çok işte çalıştıktan sonra Boston'daki bir işletme okulundan mezun olmuş ve Güney Doğu Asya'da yatırım şirketlerinde çalışmıştır. 1997 Krizi patlak vermeden hemen önce ise Tayland'da çalışmaktaydı. Çalıştı̆̆ yıllarda hem Çin'deki yükselişe hem de diğer Asya ülkelerinin finans piyasalarındaki şişmeye şahit olmuştur. Kendi ifadesiyle, o da diğerleri gibi bu yükselişin ve büyümenin sorunsuz bir şekilde işleyeceğini düşünmekteydi; fakat kriz yanıldığını gösterdi. Duncan bundan sonra Keynes, Schumpeter ve Friedman'ın külliyatına daldığını belirtmektedir. 2003 yılında çıkan The Dollar Crisis bu çabanın ürünüdür.

Duncan IMF için çalıştı̆̆ dönemdeki tecrübelerinden ilginç notlar da aktarmakta. Tayland'daki işinden 1997 krizi patlamadan hemen önce ayrıldığını, krizden sonra IMF ve Dünya Bankası'nı sürekli olarak göreve çağırdığııı belirtmekte. IMF en sonunda, kapılarını aşındırmasından bıkarak onu geçici olarak işe aldı ve Tayland'a gidecek olan IMF ve Dünya Bankası 
uzmanlarından oluşan gruba dahil etti. Grupla birlikte Tayland'a giden Duncan, grup üyelerinin Tayland ekonomisi hakkındaki cehaleti karşısında şok olduğunu ifade etmektedir. Grup 1998 y1lı için \% 3 küçülme öngördü, ancak Duncan kendi hesaplamalarına dayanarak küçülme oranının \%9 olacağını belirtti. 1998 yılında Tayland ekonomisi \% 10 küçüldü.

Söyleşi bu kısa hayat hikayesinden sonra Duncan'ın krizin kökenleri ve çözümler konusundaki düşüncelerini açıkladığı mecraya doğru akmakta. Duncan sorulan bir soru üzerine altın standardına geri dönmeyi tavsiye etmediğini vurguluyor (şu aralar bazı iktisatçılar kapitalizmin istikrarı için bunu önermektedirler). Ona göre böyle bir adım süre giden depresyonu derinleştiriyor. Kriz dinamikleri içinde öncelikli bir yer verdiği kredi genişlemesi sürecinde bu artık atılabilir bir adım olmaktan da çıkmıştır zaten. Altın standardı yerine çok uzunca bir süredir dolar standardı geçerlidir. $\mathrm{Bu}$ standart ABD'nin büyüyen bir cari açığı sürdürmesine ve finansmanı ise başkalarına yaptırmasına olanak sağlamaktadır. Duncan özellikle 1970'lerin ikinci yarısıyla birlikte başlayan kredi genişlemesini finansal patlama-ve-sönme (boom-and-burst) çevrimlerinin asli müsebbibi saymaktadır. Kontrolsüz kredi genişlemesi istikrarsızlığı arttırmakta ve özellikle gelişmiş kapitalist ülkeler için makro göstergeleri bozmaktadır. Kredi genişlemesi Keynesyen açıdan durgunluk içindeki bir ekonomide hayırlı bir durum olabilir; ancak Duncan'a göre artık kemer sıkmaya dayalı politikalar ile Keynesyen politikalar arasında bir seçim yapmaya zorunlu hissetmek, ya da bu karşıtlık üzerinde tartışmak anlamsız hale gelmiştir. Bu kadim tartışma için artık çok geçtir. Bunun nedenlerini de Duncan çok açık bir şekilde belirtmektedir. Kredi genişlemesi sürecinde hem özne hem de nesne haline gelen kapitalist devletler için atılacak adımlar belirlidir. Üstelik krizin etkisini en baskın şekilde hisseden OECD ülkelerinde her türden iktisadi ve sosyal kesim, krizi yaratan şer cephesinin üyesi gibi görünmektedir. Duncan bir yerde haklı olarak kredi genişlemesinin, Keynesyen kurgudaki talep yaratma işlevinin çok ötesinde bir işleve sahip olduğunu vurgulamaktadır. Kredi genişlemesi sadece talebi genişletmemekte, dizginsiz bir finansallaşmayı da sırtında taşımaktadır. Janus'un iki yüzü vardır; kredi genişlemesi aynı zamanda biriken borç yükü anlamına da gelmektedir.

Duncan 1964 yılında ABD ekonomisinde tüm kesimlerin borç stokunun 1 trilyon dolar olduğunu vurguladıktan sonra 2010 yılında 52 trilyon dolara yükseldiğini belirtiyor. 2010 yılında toplam kredi borcunun \% 25 ' $\mathrm{i}$ hanehalklarına, \% 27'si finans sektörüne, \% 14'ü reel sektöre ve \% 23'ü ise federal ve yerel otoriteye aittir. Kısacası ortadaki suçun sorumlusu her kesimdir; kadim tartışmaya yer yoktur. Duncan bu ölçüde bir şişmenin nedenlerini de çok sarih bir şekilde açıklamaktadır. Eğer gelirler yükselmiyor ve iş olanakları yaratılamıyor ise, varlıkların değerini geçici ve hayali bir şekilde yükseltmek tansiyonu düşürecektir. İşi olmayan, ya da işi olduğu halde 
geliri yükselmeyen sıradan Amerikalı herhalde sahip olduğu evin ya da sigorta poliçesinin değerinin hızla yükseldiğini gördüğünde mest olmuştur. Bu türden bir rahatlama kendini en hedonist yönelimlerle dışa vurdu. Amerikan toplumundaki tüketim ve yeni borçlanma çılgınlığı, Musa Peygamber Sina Dağı'ndayken toplumunun altından dökülen boğa heykeli çevresinde sergilediği çılgınlığ 1 hatırlatmaktaydı. Ancak bu rahatlama geçiciydi ve kefaret ödenmeliydi; Duncan kefaretin ne kadar büyük olduğunu gözler önüne sermektedir.

Duncan, bazı muhalif iktisatçıların aksine, dönemi nitelemek için "finansallaşma" kavramı yerine "kreditizm" kavramını tercih etmektedir. Ona göre kriz kapitalizmin değil, kreditizmin krizidir. Bu politikadan sadece devlet değil, nerdeyse tüm toplum sorumludur. Duncan'ın hesaplamalarına göre kredi genişleme oranı \% 2'nin altına düştüğü anda Amerikan ekonomisi daralmaya başlamaktadır. Böyle bir durumu Amerikan toplumunda kimse istemez. Ancak kredi-borç sarmalı hayali ve gerçeklikten kopuk bir olgu değildir; iktisadi nesnellikte mutlaka karşılığı vardır. Duncan, pek çok başka yazar gibi, bu genişlemenin düşük ücret cennetlerindeki üretim ve genişleme ile finanse edildiğinin bilincindedir. Küresel ödemeler dengesi muhasebatı içinde fazla veren ülkeler $\mathrm{ABD}$ cari açığını ve kredi genişlemesiyle şişen tüketimini finanse etmektedirler. Ortaya şöyle bir garabet çıkmaktadır; ABD sürekli dolar basmakta ve bununla yükselen ithalatını karşılamaktadır. ABD'nin açık verdiği ülkeler ise bu dolarları biriktirmekte ve yeniden $\mathrm{ABD}$ borç kağıtlarına ve finansal sistemine yatırmaktadır. Dolar ABD'nden çıkıp yeniden oraya dönmektedir. Geri dönen dolarlar ABD'nde kredi ve borç genişlemesinin temposunu arttırmaktadır. Küresel dolar çevrimi böylece Boston'lu orta sınıf bir ailenin yükselen tüketimi ile sağlanan sahte euphoria ile Shenzen'li bir işçi hanesinin bitmeyen çilesini aynı anda tesis etmektedir.

Gelişmiş kapitalist ülkelerin yüksek kamu borçlanması pahasına yaptıkları kurtarmalar ve müdahalelerle birlikte tehlike atlatıldı mı? Duncan'in cevabı olumsuzdur. Öncelikle kredi genişlemesi verdiği kısa aranın ardından kaldığ1 yerden devam ediyor gibi görünmektedir. İkinci neden olarak da küresel atıl kapasitenin yükselişini göstermektedir. Atıl kapasitenin yükselişi hiç kuşkusuz bir aşırı birikim krizinin varlığını tescil etmektedir. Dolayısı ile yakın bir vakitte, krizin bir önceki perdesinde çok fazla etkilenmeyen coğrafyaları da oluşturduğu girdaba çekecek, yeni bir kriz perdesiyle karşı karşıya kalacağız gibi görünmektedir.

Peki çözüm? Duncan küresel talebi arttırmayı öneriyor. Ancak bunun için önerdiği coğrafya ucuz emek cennetleri. Tam da bu noktada ilginç bir öneri getiriyor. Ucuz emek sağlayan ve dış ticaret fazlası veren ülkeler, tıpkı petrol üreten ülkelerin OPEC örneğinde sergiledikleri tutumu tekrarlayarak bir emek 
karteli oluşturabilirler. Böylece emek güçlerine ödenen ücretleri ve dolayısıyla talebi arttırabilirler. Fakat bu bir politik çözümdür; ideolojik karşı çıkışlar bir yana, meslekten iktisatçıların hoşuna gitmeyebilir. İşin bu yönüyle ilgilenmiyor gibi görünen Duncan krize ve durgunluğa getirilen çözümlerin de aslında iktisat dışı siyasal bir düzlemden geldiğinin farkındadır. Örneğin 1980'lerde dış ticaret açığı büyüme trendine giren $\mathrm{ABD}$, doların değerinin düşük tutulması planını Plaza Anlaşması ile Almanya ve Japonya'ya kabul ettirmiştir. Keza son zamanlarda Çin'e yönelik ulusal para birimini revalüe etmesi yönünde yoğun bir baskı vardır. Kapitalizmin derinleşen krizine getirilen çözümler, doğası gereği politik olmak durumundadır. Duncan bunun bilincindedir ve onun önerisi de politiktir.

Duncan meslekten bir iktisatçı değil; mesleki tecrübe ve sağduyu ile konuşan bir araştırmacı. Bir akademik formasyon bazı durumlarda oldukça tutucu ve duyarsız olabilmektedir. Bilimler tarihi bu konuda pek çok örnek sunacaktır. Krizin belirteçleri artık sansürlenemeyecek ve yok sayllamayacak hale geldiğinde bile işlerin iyi gittiğini belirtmekten vazgeçmeyen Batılı iktisat akdemyasının büyük bir bölümünün tutumu buna çarpıcı bir örnektir. ${ }^{1}$ Bazı durumlarda özellikle ideolojik donanımları yüksek sosyal bilim disiplinlerine dışarıdan bakmak daha elverişli olabilmektedir. Duncan'la yapılan söyleşi bu açıdan ilginç bir vesikadır.

\footnotetext{
${ }^{1}$ Charles Ferguson'un yönetmenliğini yaptığı Inside Job adlı belgesel kriz öncesinde bu tutuma sıkıca bağlı kalan bazı iktisatçılar ile söyleşileri içermektedir. Kriz patladıktan sonra bile kendi tutumlarını aklama ve olumlama çabaları birer kara mizah örneği olarak algılanmalıdır.
} 